\title{
Perceived economic burden associated with an inherited cardiac condition: a qualitative inquiry with families affected by arrhythmogenic right ventricular cardiomyopathy
}

\author{
Holly Etchegary, $\mathrm{PhD}^{1}$, Glenn Enright, BSc${ }^{2}$, Rick Audas, $\mathrm{PhD}^{3}$, Daryl Pullman, $\mathrm{PhD}^{3}$, \\ Terry-Lynn Young, $\mathrm{PhD}^{4}$, and Kathy Hodgkinson, $\mathrm{PhD}^{1,4}$
}

Purpose: Significant gaps remain in the literature on the economic burden of genetic illness. We explored perceived economic burden associated with one inherited cardiac condition, arrhythmogenic right ventricular cardiomyopathy (ARVC).

Methods: Semistructured interviews were held with individuals from families affected by ARVC. Data on the perceived financial and economic impacts of ARVC were used to identify emerging categories and themes using the method of constant comparison.

Results: Data analysis revealed four themes that described participants' perceptions of the economic impact ARVC had on them and their families: (i) economic impact during childhood, (ii) impact on current and future employment, (iii) impact on current and future financial well-being, and (iv) no perceived economic impact.

Conclusions: This study is the first to explore the economic burden of ARVC from the perspective of affected families. It revealed a number of perceived burdens, from employment and career choices to worry about insurance for self and children, decreased household spending, and the need for childhood employment. Findings highlight potential areas of discussion for genetic counseling sessions, as well as areas for future research.

Genet Med advance online publication 29 October 2015

Key Words: arrhythmogenic right ventricular cardiomyopathy; burden; economic; inherited; qualitative

\section{INTRODUCTION}

Chronic illness and disability have damaging economic effects for individuals and families. Economic costs are incurred through lost productivity and wages as a result of disability and early mortality, unaffected family members becoming caregivers for a sick family member, as well as direct costs (e.g., medications). Intangible costs can be incurred through lower investments and savings or reduced educational attainment. ${ }^{1,2}$ The loss of income due to illness may result in a change of economic outlook, the need to use savings, bankruptcy, decreased quality of work, and fewer employment opportunities. ${ }^{1-5}$ All of these represent the economic burden of a disease.

The greater the perceived economic burden, the lower the quality of life of cancer survivors ${ }^{4}$ and others who suffer from chronic illness. ${ }^{2,3}$ Although lower-income patients spend a higher percentage of their income on expenses related to chronic conditions, higher-income patients also have significant out-of-pocket costs. The literature on the economic burden of illness suggests that all patients may face economic hardship of some type that is exacerbated by factors such as comorbidities, ineligibility for government support, and minority ethnic background. ${ }^{3}$

Most research focuses on the experiences of those with cancer or other common chronic diseases; less attention is given to patients affected by genetic conditions, which collectively affect a significant portion of the population. ${ }^{6}$ Economic burdens may be further heightened for those affected by genetic disorders because worry extends to their children who are at risk and their children's financial futures. In this article, we explore the perceived economic burden associated with one inherited cardiac condition, arrhythmogenic right ventricular cardiomyopathy (ARVC).

ARVC is a single-gene disorder of the heart muscle, marked by pathologic changes within the myocardium and dilation of one or both ventricles. A progressive disease, ARVC culminates in life-threatening ventricular tachyarrhythmias that cause sudden cardiac death (SCD) and/or heart failure. ${ }^{7-9}$ ARVC is responsible for up to $20 \%$ of SCD cases, particularly among young athletes. ${ }^{8,9}$ The prevalence of ARVC is estimated between 1 in 2,000-5,000. ${ }^{8}$ However, because the disease is difficult to diagnose and has an age-related penetrance, the actual prevalence may be higher. ${ }^{10,11}$ In Newfoundland and Labrador (NL), Canada, many cases of familial SCD resulting from lethal ventricular tachyarrhythmias ${ }^{11}$ are caused by a founder mutation in TMEM43 (p.S358L). ${ }^{12}$ This genetic subtype of ARVC is lethal, particularly in males, with a median age at death of 41 years compared with 71 years in females. ${ }^{13}$ This variant of ARVC is

\footnotetext{
Clinical Epidemiology, Faculty of Medicine, Memorial University, St. John's, Newfoundland, Canada; ${ }^{2}$ Faculty of Nursing, University of Toronto, Toronto, Ontario, Canada; ${ }^{3}$ Community Health and Humanities, Faculty of Medicine, Memorial University, St. John's, Newfoundland, Canada; ${ }^{4}$ Discipline of Genetics, Memorial University, St. John's, Newfoundland, Canada. Correspondence: Holly Etchegary (holly.etchegary@med.mun.ca)
}

Submitted 20 March 2015; accepted 18 August 2015; advance online publication 29 October 2015. doi:10.1038/gim.2015.132 
fully penetrant over the life span and is inherited in an autosomal-dominant manner (i.e., offspring of the affected parent are at $50 \%$ risk of inheriting the TMEM43 mutation). The only available intervention is an implantable cardioverter-defibrillator (ICD), which shocks the heart to a normal sinus rhythm if ventricular dysrhythmias are noted, thus preventing SCD. Patients with ARVC might also be advised to avoid competitive athletics and limit activity to low- or moderate-intensity activities such as walking. Those in careers involving physical strain or situations where they could be a danger to themselves or others should they experience syncope might be advised to consider a career change..$^{8,9}$

Cardiac guidelines support the use of familial cascade screening to identify blood relatives who carry pathogenic ARVC mutations before clinical signs develop. ${ }^{14,15}$ For those who are positive, an ICD is recommended. ${ }^{8,9,16}$ ICDs had a beneficial effect in several studies, notably in the NL population, among whom the treatment significantly altered the survival of individuals in families with ARVC TMEM43 p.S358L. ${ }^{17,18}$ At-risk relatives provided with an ICD are often young, unaffected family members. They will likely have many years with their ICD, exposing them to repeated procedures, shocks, ICD complications, and lifelong psychosocial burdens. ${ }^{19,20}$

Though the economic burden of prophylactic management of ARVC may be considerable, there are no studies exploring this burden from the perspective of affected families. The obvious cost of years of life and associated income lost as a result of SCD is tangible, as are related costs for caregivers who refrain from paid employment. Other costs may include higher insurance premiums, medications, and travel for lifelong management of the condition, as well as other impacts such as lower savings and educational attainment. We identified 24 families with ARVC caused by TMEM43 p.S358L in the NL population, providing a unique opportunity to explore the perspectives of individuals who live with this chronic condition in order to inform the provision of patient-centered health services and add to the literature on the economic hardship associated with chronic genetic disorders.

\section{MATERIALS AND METHODS}

\section{Sampling and recruitment}

The project was approved by the local health research ethics authority. Participants were recruited from the provincial cardiac genetics clinic in St. John's, NL. Clinic participants receive genetic counseling, testing, and follow-up clinical management. Per guidelines, at-risk family members are evaluated in a stepwise manner (cascade testing) after a pathogenic mutation is identified in the family. ${ }^{14,15}$ Carriers are offered ongoing cardiac screening, lifestyle advice, pharmacological treatment, as well as an ICD, which are known to significantly improve survival in this population. ${ }^{18}$

A cardiomyopathy genetics research clinic was initiated in Newfoundland in 1998. Concomitantly, a research computer database (SPSS) was established to support and maintain local research on ARVC. Data for individuals from families affected by ARVC in the province are stored in this database, including expanded pedigrees, clinical information, demographic information, as well as any research data collected. The ARVC database contains information on 885 individuals, 275 of whom are living and were eligible for this study. Before sending study invitation letters, K.H. and H.E. met to discuss the spectrum of experience with ARVC to be captured in interviews (e.g., individuals testing positive, testing negative, and declining testing). K.H. has a long-standing relationship with families affected by ARVC in NL, and she identified individuals in the database through purposive sampling to represent a broad spectrum of experience with ARVC (e.g., those who are currently asymptomatic, carriers and noncarriers of TMEM43, those with/ without ICD). When possible, and to maximize recruitment, five or six individuals from each of these groups were identified for study invitations. Partners/spouses also were invited to a separate interview because their views would be informative of the disorder's impact on the broader family. Adolescents (age 14-18 years at the time of interviews) in these families could also take part. Invitation letters were sent to 73 individuals in total, and participants were invited to contact the research team if they were interested in participating.

\section{Interviews}

Interviews were conducted in person August through December 2013, with a minority $(n=3)$ occurring by phone. A trained interviewer with the Health Research Unit at Memorial University conducted interviews outside of clinic appointments at a time that was convenient for participants. Interviews lasted 45-60 min, were tape-recorded and then transcribed verbatim. Interviews were semistructured in that questions were not strictly confined to a specific order, and participants were actively encouraged to discuss other issues that they felt were important. An interview guide facilitated the tracking of all questions asked during each interview.

This qualitative study was part of a larger program of research on the psychosocial impacts of living with ARVC. Interviews covered a core set of topics such as family experiences of heart disease and SCD, ICD surgery decisions, and the perceived impact of ARVC across a number of domains such as psychological well-being, behavioral impacts, and perceived financial or economic impact. Draft questions were generated by H.E. in line with study aims. Subsequent discussion of question wording with the research team, as well as review by a genetic counselor, resulted in only minor changes to question wording. Please see the Appendix for the final interview guide.

\section{Data analysis}

Qualitative description ${ }^{21}$ was used to summarize the data pertaining to the perceived economic impacts of ARVC. This is a form of naturalistic inquiry that makes no philosophical or theoretical assumptions about the data. Instead, it presents the data in the language of participants, without necessarily aiming to interpret the data in more theoretical ways. The end result is a comprehensive summary of the event in question. ${ }^{21}$ 
H.E. read transcripts as interviews were completed to identify emerging ideas and themes. When possible, interviews proceeded until data saturation was reached (i.e., the point at which no new ideas were emerging). In some cases (e.g., adolescent and spouse interviews), we did not reach saturation within the study timeline, as noted in the discussion of study limitations in the Conclusion section. The complete set of transcripts was read several times by one investigator (H.E.). Interview data were then isolated and organized around interview topics. Only data pertaining to the perceived financial and economic impacts of ARVC were used to identify emerging categories and themes for this analysis. Two investigators (H.E., K.H.) separately read and reread the isolated economic data, which was placed in a table. Inductive subcoding of these data was completed using the method of constant comparison..$^{22,23}$ Data were compared between and within transcripts to establish analytical categories and themes. ${ }^{21-23}$ This method required a constant shifting back and forth between (and within) transcripts to continuously compare the experiences of participants. When both investigators had completed their separate analysis, they met to discuss categories and themes that arose from the data. While investigators may have used slightly different wording to categorize data, agreement was very high regarding the basic ideas reflected in each theme. Following their meeting, the investigators then met with the study interviewer who had spoken with participants and was familiar with their stories. Further discussion with her helped verify emerging themes. Finally, an analysis meeting was held with the study team to present, discuss, and finalize themes.

\section{RESULTS}

\section{Participants}

Seventy-three study invitation letters were sent; five were returned as undeliverable. In total, 21 individuals ( 5 men) contacted the research team and completed an interview. All families had been followed clinically for many years and were known to the research team. Nonresponders included those who had heart transplants and those who declined genetic testing. Table 1 contains clinical and demographic information for the study participants. Of the 17 participants who had genetic testing, 9 tested positive for TMEM43 (at the time of testing, 2 were adolescents aged 14-18 years). Eight of these 9 participants had an ICD; the youngest participant did not. Before 2008, genetic disease status was given to participants based on haplotype analysis and was confirmed when mutation testing became available after 2008. All participants had a history of SCD in their families, and this was often the initial reason for evaluation by the clinical team. Four spouses completed interviews; all were wives whose husbands had tested positive for TMEM43 (two of these husbands completed interviews). Participants' current ages ranged from 16-67 years, with a mean age of 44 years (SD $=14$ years). Excepting the adolescents, nearly all participants were married with children. While we lack quantitative data on mean incomes, the long experience and contact of research team members with families suggests that most participants are currently from middle-class backgrounds.

\section{Thematic analysis}

Four themes describe participants' perceptions of the economic impact of ARVC: (i) economic impact during childhood, (ii) impact on current and future employment, (iii) impact on current and future financial well-being, and (iv) no perceived economic impact. We note that the first three themes were not mutually exclusive. Participants could recall burdens they experienced during childhood, while also recounting impacts on current employment or financial well-being.

\section{Economic impact during childhood}

Participants whose fathers had died or were unable to work during their adolescence recalled feeling "different" from other families. Necessities were available, but there were no "extras."

\begin{abstract}
"We had a house full of mostly male boarders. It was our home, but it was also Mom's livelihood. I guess it robbed us of a whole lot of life because Mom had to work really hard. I never felt deprived of love, but it was different growing up. I was the last kid in the neighborhood to get a bike... Why don't we have a TV? Everybody else has a TV.' (P14, unaffected female)

"Huge, huge [financial impact]. My Dad had to stop working and go on long-term disability. We didn't have a whole lot, and we all started working ourselves as kids, probably $13,14 \ldots$ there weren't those extras...we never went hungry, we were never cold, we always had clothes, but anything above and beyond that was harder to get". (P10, unaffected female)
\end{abstract}

As the latter participant alluded, children in families affected by ARVC sometimes had to work to supplement the family income. For some, this manifested as a feeling of having to contribute.

"It was just financial stress put on the family, and I felt like I had to be the one that had to toe the line. And my younger sister, if there wasn't enough money to buy lunch at school, she'd go to school and I'd stay home. I just started getting jobs young." (P13, unaffected male)

"I was working in the fish plant at 11 years old. Now how many can say they started working at 11 years old to help support their family?" (P1, unaffected female)

\section{Impact on current and future employment}

When a person is clinically affected with ARVC, there are obvious limitations on the types of jobs that can be safely undertaken, as well as recovery time following ICD surgery. The quality of work experiences also declines.

"Financial impact? Oh God yes. I went back to work, and I was allowed to go for two half days a week and build up from there. It was months before I got back full time...it's probably $25 \%$ of my job that I can't do anymore...as time has gone on, I've done less and less...there's times when 
Table 1 Clinical and demographic characteristics of study participants

\begin{tabular}{|c|c|c|c|c|c|c|c|c|c|c|}
\hline Sex & $I^{a}$ & $\begin{array}{l}\text { Family } \\
\text { ID }^{\mathrm{b}}\end{array}$ & $\begin{array}{c}\text { Age } \\
\text { (years) }\end{array}$ & $\begin{array}{l}\text { Method } \\
\text { of } \\
\text { diagnosis }\end{array}$ & $\begin{array}{c}\text { Family history of } \\
\text { sudden cardiac } \\
\text { death? }\end{array}$ & $\begin{array}{c}\text { Clinical signs } \\
\text { of disease at } \\
\text { presentation? }\end{array}$ & $\begin{array}{l}\text { TMEM43 } \\
\text { p.S358L } \\
\text { mutation } \\
\text { status }\end{array}$ & $\begin{array}{l}\text { ICD (year } \\
\text { implanted) }\end{array}$ & $\begin{array}{l}\text { Perceived } \\
\text { economic } \\
\text { impact? }\end{array}$ & $\begin{array}{c}\text { Affected } \\
\text { parent? }\end{array}$ \\
\hline $\mathrm{F}$ & P14 & AR1 & 64 & $\begin{array}{l}\text { Genetic } \\
\text { testing }\end{array}$ & $1^{\circ}$ SCD 26 years & No & Negative & No & Yes & Father \\
\hline $\mathrm{F}$ & P2 & AR1 & 67 & $\begin{array}{l}\text { Genetic } \\
\text { testing }\end{array}$ & $2^{\circ}$ SCD 29 years & No & Negative & No & Yes & Father \\
\hline $\mathrm{F}$ & P6 & AR2 & 46 & $\begin{array}{l}\text { Genetic } \\
\text { testing }\end{array}$ & $3^{\circ}$ SCD 39 years & Yes & Positive & Yes (2009) & No & Mother \\
\hline $\mathrm{F}$ & P11 & AR2 & 16 & $\begin{array}{l}\text { Genetic } \\
\text { testing }\end{array}$ & $\begin{array}{c}1^{\circ} \mathrm{ICD} \text { with } \\
\text { several firings, } \\
2^{\circ} \mathrm{HT}, 5^{\circ} \text { SCD } 38 \\
\text { years }\end{array}$ & No & Positive & No & Yes & Father \\
\hline M & P13 & AR2 & 44 & $\begin{array}{l}\text { Genetic } \\
\text { testing }\end{array}$ & $3^{\circ} \mathrm{SCD}$ & No & Negative & No & Yes & Father \\
\hline M & P15 & AR2 & 47 & $\begin{array}{l}\text { Genetic } \\
\text { testing }\end{array}$ & $3^{\circ}$ SCD 38 years & Yes & Positive & Yes (2008) & Yes & Mother \\
\hline $\mathrm{F}$ & P16 & AR2 & 60 & $\begin{array}{l}\text { Genetic } \\
\text { testing }\end{array}$ & $\begin{array}{l}1^{\circ} \mathrm{SCD} 30 \text { years, } \\
2^{\circ} \mathrm{SCD} 38 \text { years }\end{array}$ & No & Negative & No & Yes & Mother \\
\hline $\mathrm{F}$ & P9 & AR2 & 46 & $\begin{array}{l}\text { Genetic } \\
\text { testing }\end{array}$ & $3^{\circ}$ SCD 39 years & No & Negative & No & No & Mother \\
\hline $\mathrm{F}$ & P1 & AR2 & 40 & $\begin{array}{l}\text { Genetic } \\
\text { testing }\end{array}$ & $\begin{array}{c}3^{\circ} \text { SCD } 39 \text { years, } \\
1^{\circ} \mathrm{HT} 55 \text { years }\end{array}$ & No & Negative & No & Yes & Father \\
\hline $\begin{array}{l}\text { F Spouse } \\
\text { (husband is P15) }\end{array}$ & P18 & AR2 & 47 & N/A & $N / A$ & N/A & N/A & N/A & Yes & $\begin{array}{l}\text { Spouse's } \\
\text { mother }\end{array}$ \\
\hline $\begin{array}{l}\text { F Spouse } \\
\text { (husband did not } \\
\text { do interview) }\end{array}$ & P20 & AR11 & 42 & N/A & N/A & N/A & N/A & $\mathrm{N} / \mathrm{A}$ & Yes & $\begin{array}{l}\text { Spouse's } \\
\text { mother }\end{array}$ \\
\hline $\mathrm{F}$ & P10 & AR12 & 26 & $\begin{array}{l}\text { Genetic } \\
\text { testing }\end{array}$ & $2^{\circ}$ SCD 30 years & No & Negative & No & Yes & Father \\
\hline $\begin{array}{l}\text { F Spouse } \\
\text { (husband did not } \\
\text { do interview) }\end{array}$ & P21 & AR15 & 37 & N/A & N/A & N/A & N/A & $\mathrm{N} / \mathrm{A}$ & No & $\begin{array}{l}\text { Spouse's } \\
\text { father }\end{array}$ \\
\hline M & P17 & AR15 & 37 & $\begin{array}{l}\text { Genetic } \\
\text { testing }\end{array}$ & $1^{\circ} \mathrm{SCD} 25$ years & Yes & Positive & Yes (2007) & No & Father \\
\hline $\begin{array}{l}\text { F Spouse } \\
\text { (husband P17) }\end{array}$ & P19ÂÂ & AR15 & 38 & N/A & N/A & N/A & N/A & N/A & & $\begin{array}{l}\text { Spouse's } \\
\text { father }\end{array}$ \\
\hline
\end{tabular}

Clinical screening: family originally referred for a familial "heart disease." Family members were invited to the clinic for cardiac screening. Pedigree: known TMEM43 family. Extended relatives at 50\% pedigree risk ascertained. Genetic testing offered.

Participants 11 and 12 underwent presymptomatic testing; all others were tested to confirm a suspected mutation status.

Family history of sudden cardiac death $(S C D)$-numbers indicates which degree relative experienced SCD.

$H T$, heart transplant; ICD, implantable cardiac defibrillator; N/A, not applicable.

aRefers to participant study ID number. ${ }^{b}$ The family numbers are listed above, the pedigrees for which can be seen in ref. $12 .{ }^{~}{ }^{C}$ urrent age. 


\section{ORIGINAL RESEARCH ARTICLE}

something needs to be done and you want to do it, but you know if you do, you're putting yourself at risk. And you got to wait on people to get stuff done." (P15, affected male)

"So I haven't worked in a long time and that part gets to me. There's lots of jobs out there I'd like to have, and I know physically, I can't do them...that bugs me; you're limited." (P4, affected female)

"I was getting close to retirement, but I probably would have stayed on another year. I resented that for a long time; I wasn't able to retire at the time when I wanted to. ARVC prevented me from doing that, it was very stressful." (P5, affected female)

For a young adolescent male in our sample, he noted his frustration that his future career choices were limited by ARVC. He explained his desire to join the military:

"It sucks a lot. I'm just as good of a shot as cracky over there who's probably smoking drugs all his life and can get in just fine [to the military], but I've got a heart condition and I'm sidelined. I want to do something productive." (P12, affected male)

The careers of spouses of affected individuals can also be affected by ARVC. For some, this meant returning to work earlier than desired.

"[My husband] used to work a lot of overtime hours, which padded the family finances quite a bit. At the time he had his surgery, I was working in a part-time position because it meant that I could be around more for the children. But I ended up going back to work fulltime because we needed the money." (P18, spouse of affected male)

\section{Impact on current and future financial well-being}

The ability to work directly affects a family's disposable income, as participant narratives on the economic impacts of ARVC in childhood show.

"It takes a financial strike on you, because every time Dad was in hospital, if I didn't have the money, I had several Visas, and everything was racked up, so I claimed bankruptcy...by the time the bills are paid and a minimum amount of groceries, it's probably five or six dollars left for the whole month, so I would flick the Visa and get gas, and flick the Visa and get food" (P1, unaffected female)

Families that live outside an area served by a main treatment center must contend with the direct cost of treatment.

"Financially, it's been a big impact. I mean, we're from [a certain region] and no one recognizes that. They think we live next door to the [main treatment center]. One year, it cost me about $\$ 1200$. Ambulance trips, and paying for the nurse, and you're back and forth paying for hotels, it's stressful." (P20, spouse of affected male)
ARVC affects families' financial outlook not only in such direct ways but also in other ways, from worry about having enough insurance to worry about children's futures and longterm financial planning.

"I know Mom had trouble getting insurance...if I wanted to up my life insurance at work, I'd have to sell my soul to pay the premiums, right? But you're kind of penalized when it comes to insurances, and when you're young, you don't think about that stuff, but when you get older and have kids, everything changes, you're high risk." (P3, affected female)

"You lose your life insurance and you got this in [referring to ICD]. So that's a big thing. Like I'm very thankful they put one in for free." (P7, affected female)

"I was unemployed. We applied for additional insurance that was denied. If there comes a point where I can't work, then I lose my benefits, and the drugs are not cheap (pause)...it can be nasty, and if somebody's off longer than the unemployment lasts, and they don't have long-term disability, then you got nothing." (P15, affected male)

For participants with good insurance plans at work and/or a supportive employer, financial worries were reduced.

"So we're very lucky that his company supports him and kept his position for him...his work actually put off putting in longterm disability until he came back to work and had enough hours to qualify, which was really good of them because we had nothing to fall back on." (P18, spouse of affected male)

"I'm lucky. I had good health insurance coverage, my husband has good health insurance coverage, so I can't think it has [impacted me financially], except for losing the license [after ICD firings]. I checked out taking taxis to work, and it would have cost me $\$ 600, \$ 700$ a month just to go back and forth there." (P5, affected female)

Although current financial worries were eased by good insurance coverage, participants worried about their children's financial futures.

"You're thinking of all the bad things that can happen. My God, I could be raising these two kids by myself. How am I going to pay for this house? How am I going to make car payments? I see a scarier future. My concentration and drive now is to get the children through school and into a career where they're settled and making enough money to support themselves." (P18, spouse of affected male)

Finally, some participants explained how their long-term outlook changed as a result of the uncertainty associated with ARVC.

"I don't like planning stuff much anymore because I don't know what's going to happen. I don't even plan what I'm going to do tomorrow." (P12, affected male) 
"We've changed our priorities a lot; we want to travel more, we want to do more things together while we can, and spend time with the kids. Before that, it was all about paying off bills, but if he's not going to be here in five years, I would just as soon take this time with him and the bills will still be there. So I think that's the biggest way it's impacted us; we are not planning for retirement, but what we want to get done and our bucket list so to speak." (P18, spouse of affected male)

\section{No perceived economic impact}

A minority of participants did not perceive a significant economic impact of ARVC. Some said they were currently asymptomatic and had resumed normal activities, although recognizing that perhaps they shouldn't.

\begin{abstract}
"Right now, I'm completely healthy. The only impact it has on me obviously is the surgery itself. For me, my life hasn't changed at all because of it. I'm still very active, I'm still working more than I should, and I'm enjoying life, so it really hasn't impacted me at all you know." (P17, affected male)

"I do things I'm not supposed to be doing...I don't generally let it slow me down. I do what I'm not supposed to do and I (pause)...it can't slow me down because otherwise, I'd curl up in a corner and stay there." (P6, affected female)
\end{abstract}

An unaffected participant who lived out of the province suggested that this geographic distance may explain why she perceived no immediate impact, economic or otherwise:

\begin{abstract}
"No, I don't think so. I mean, maybe if I was there and seeing it every day...but being so far removed, so far away, so no." (P9, unaffected female)
\end{abstract}

Finally, one spouse commented that, although there was no current economic impact on her family, that would change if the disease progressed:

\begin{abstract}
"Financially, it hasn't affected us. If he gets very unhealthy and we need to travel to get him a new heart or wait on transplant, then it will, of course. But as of right now, no, it hasn't at all." (P21, spouse of affected male)
\end{abstract}

\section{DISCUSSION}

Rare genetic diseases are chronic and life-limiting, accompanied by extensive morbidity, health system utilization, and psychosocial and financial stress for families. ${ }^{24-27}$ Despite this, relatively little is known about their associated economic burden beyond direct medical costs. ${ }^{24,25}$ However, a more comprehensive understanding of disease burden, including nonclinical burdens such as financial impact, is required to personalize disease management according to families' needs. ${ }^{28}$ Identification of both direct and indirect costs associated with chronic genetic conditions is of further importance to policymakers in order to develop sustainable and patient-centered health policy options for families affected by rare diseases. For example, economic burden data may assist in developing effective intervention programs, facilitate treatment evaluation, and potentially inform the development of financial support policies for patients and their families. ${ }^{24-26}$

A recent systematic review of cost of illness evidence across 10 rare diseases (most of them genetic) reported that cost evidence was meager for all but two disorders: cystic fibrosis and hemophilia. ${ }^{25}$ Nonetheless, the review found a substantial economic burden of rare diseases, including both direct costs (e.g., treatment) and indirect costs-in particular, productivity losses incurred by informal caregivers. Similarly, a recent study ${ }^{24}$ of the burden of Duchenne muscular dystrophy, an X-linked neuromuscular disorder, reported mean annual direct per-patient costs of between $\$ 23,000$ and $\$ 55,000$. This study also measured indirect and informal care costs, finding that they accounted for between 18 and $43 \%$ of total costs. For example, very few patients were employed, and between 27 and $49 \%$ of informal caregivers had either stopped working or had reduced working hours. Similarly, patients with hereditary angioedema reported work impairment and negative effects on career advancement. ${ }^{28}$

Some of this study's participants noted the direct travel and medication costs associated with management of ARVC, in line with recent research on rare diseases. ${ }^{24-26}$ Some families affected by Lynch syndrome in our jurisdiction have also suggested that prohibitive costs are a barrier to recommended colon cancer screening and ongoing risk management. ${ }^{29}$

Beyond these direct costs, however, study findings revealed the breadth of perceived economic impact associated with ARVC, consistent with a recent systematic review that suggested that indirect costs were as burdensome for sufferers of rare diseases as direct costs. ${ }^{25}$ Even unaffected participants can perceive significant economic burden. Their narratives revealed serious burdens during childhood that often resulted in childhood employment and left these participants feeling somehow "different" from peers. While they ultimately tested negative for the family mutation, it is likely that ongoing psychosocial support for these children at the time of their parent's illness could have facilitated their psychosocial adjustment. Information for the family on health and social care programs in their jurisdiction might also have obviated the need for childhood employment. It is notable that these participants had affected fathers, which might be a red flag for potential economic burden during childhood.

Although children and teens are managed clinically by the cardiac genetics clinic in our jurisdiction, it is unknown whether professional support services address economic burdens. The literature on other disorders (e.g., Huntington disease) suggests that accessing appropriate support may be important for children who help to provide care to their affected relatives or perceive themselves as having to contribute to the family finances and day-to-day functioning. The limited 
research in this area reveals that it is a demanding role with the potential for negative developmental impacts and emotional distress, ${ }^{30,31}$ which may be exacerbated by their own risk for the family mutation. Research is needed to determine the factors that could minimize negative outcomes for children in families affected by ARVC. Determining which children require support and how they should best be supported is a research priority. Interdisciplinary, team-based care might afford families access to the nonclinical information they may also need (e.g., care assistance programs, financial programs) to manage their condition.

Despite universal health care coverage and an established system of social security, those with chronic illness can still face lifelong economic hardship and quality of life impairment, and lack the resources to cope with these challenges. ${ }^{3,4,25,26}$ Although participants with supportive employers and good insurance coverage perceived a lower economic burden than participants without these protections, study narratives suggest that a discussion of the family's economic situation may be a useful addition to genetic counseling sessions. ${ }^{32,33}$ Indeed, at-risk individuals need to know that a positive test result generally makes them ineligible for life insurance. Some have access to group insurance through an employer, but this is probably not true for most, and even this would not be available to individuals who can no longer work.

Similar to the findings of research ${ }^{3,5,28,30}$ on other chronic illnesses and rare diseases, ${ }^{24,28}$ affected individuals recounted how ARVC affected both their ability to work and the quality of their work experiences, as well as its effect on their financial wellbeing. Underlying these narratives is a changed sense of self, one that can no longer maintain former employment trajectories and must worry about coping with the continued economic impact of ARVC on their families.

Classic studies of chronic illness ${ }^{34-36}$ confirm that illness "disrupts" an individual's biography, leading to changing roles and identities. Affected participants described their changing roles at work from not being able to carry out prior duties to having to wait on others to complete tasks and having to retire earlier than they wanted. For younger participants, ARVC affected their future career choices. Participants noted increased insurance premiums and worry about losing insurance if their disease worsens and they cannot work. These experiences relating to career and insurance may lead to psychological distress and lower life satisfaction, ${ }^{4,37-39}$ and they highlight areas of concern to be addressed in a holistic model of care. In particular, participant narratives raise awareness of the potential breadth of economic impact for patients, and we encourage clinicians working with affected families to actively communicate about these issues during clinic encounters. Research aimed at exploring clinician awareness of the economic impacts associated with ARVC and similar genetic disorders, as well as interventions designed to improve awareness and patient-clinician communication about economic burdens, would be valuable.

A minority of participants experienced no economic burden as a result of ARVC. Those who tested negative and were living out of the province suggested that their distance from the family illness muted its impact on their lives, whereas others said that they were asymptomatic and had continued to work. These explanations correspond to the larger literature on genetic conditions, which suggests that being asymptomatic or somehow "removed" from the family illness (whether geographically or socially) reduces its perceived psychological impact. ${ }^{30,31,40}$

\section{Conclusion}

This is the first study to explore the economic burden of ARVC from the perspective of affected individuals. A number of perceived burdens were identified, including employment choices, worry about insurance, and the need for childhood employment. Findings highlight potential areas of discussion in counseling sessions, as well as areas for future research. However, the sample size is relatively small, comprising mostly individuals affected by a specific genetic subtype of ARVC (ARVD5). The study was conducted in a comprehensive clinical service; findings may not generalize to patients seen outside such centers. All participants had undergone testing; thus they may display specific perceptions that cannot be generalized to all atrisk individuals. For example, we were unable to recruit those who declined testing and those who had progressed to heart transplants in their disease progression. We were also unable to recruit families that had known about their risk for a short time. Rather, the families in this study had all known about ARVC for a period of years. Adolescents and spouses were underrepresented in this sample. Additional research that focuses solely on spouses or adolescents in families with ARVC would be informative. Despite these limitations, this study is the first to explore the economic burden of ARVC from the perspective of affected families. We hope these findings contribute to patientcentered health and social care policies and research.

\section{APPENDIX: PSYCHOSOCIAL IMPACTS INTERVIEW GUIDE USED FOR THE STUDY}

Meta-question: family's experience with ARVC?

1. Can you tell me how you came to discover you personally were at risk for ARVC?

(Probe: were you aware of a family history of heart disease? Was heart disease/ARVC talked about in your family?)

2. What comes to mind when you think about ARVC in your family?

(Probes/follow-up: what does ARVC mean to you? How does the history of ARVC in your family make you feel?)

Meta-question: genetic testing decision?

1. Can you tell me about your thoughts about genetic testing? (Probes: what things did you think about in making a decision? How did you come to a decision? Did you feel any duty to pursue testing?) 
Meta-question: living with the result

1. What results were you told you could have? Did you feel you were prepared for any of the possible results?

2. How do feel now that you have this result? Tell me how this result has had an impact on you. (Emotionally? Physically? Your relationships with others? Behavioral or lifestyle changes? Has there been any financial impact on you or your family because of this illness?)

3. For those who declined testing: have you ever regretted your decision to decline testing? What impact does living with an increased risk for ARVC and possible SCD have on your life?

Meta-question: talk to me about what these results mean for your health (health care).

1. What do you think you will do differently (or have done differently), if anything, now that you know these results?

a. For those who have ICDs implanted: tell me what it's been like to have the ICD? How do you feel about it?

2. What did you think of the recommendations given to you by your health-care provider(s)?

a. Can you remember them?

3. Do you plan on following these recommendations? Have you already started or do you have an idea of how you are going to follow through with these plans (or make the decisions you are facing)?

4. For those who declined testing: were you given any health recommendations because of your family risk? What do you think of these? Does knowing you are at risk affect the decisions you make about your health or health care?

Meta-question: family impact of testing for ARVC?

1. For those who have been tested: do you think your genetic test result has implications for your family? (Probe: for which family members do you think your result has implications? What are they?)

2. What are the advantages in talking with your family about your genetic test result/decision? What are the disadvantages?

Meta-question: do you have any suggestions for us about the kind of information or support that is needed for families affected by this condition in the province?

Is there anything else you would like to add or think we should know?

\section{ACKNOWLEDGMENTS}

The authors thank the families for their time and participation. Financial support was provided by the Atlantic Canada Opportunities Agency and Genome Canada.

\section{DISCLOSURE}

The authors declare no conflict of interest.

\section{REFERENCES}

1. Kelly BB, Narula J, Fuster V. Recognizing global burden of cardiovascular disease and related chronic diseases. Mt Sinai J Med 2012;79:632-640.

2. Valtorta NK, Hanratty B. Socioeconomic variation in the financial consequences of ill health for older people with chronic diseases: a systematic review. Maturitas 2013;74:313-333.

3. Jeon YH, Essue B, Jan S, Wells R, Whitworth JA. Economic hardship associated with managing chronic illness: a qualitative inquiry. BMC Health Serv Res 2009;9:182.

4. Meneses K, Azuero A, Hassey L, McNees P, Pisu M. Does economic burden influence quality of life in breast cancer survivors? Gynecol Oncol 2012;124:437-443.

5. Rasmussen DM, Elverdam B. The meaning of work and working life after cancer: an interview study. Psychooncology 2008;17:1232-1238.

6. McCandless SE, Brunger JW, Cassidy SB. The burden of genetic disease on inpatient care in a children's hospital. Am J Hum Genet 2004;74:121-127.

7. Marcus Fl, Edson S, Towbin JA. Genetics of arrhythmogenic right ventricular cardiomyopathy: a practical guide for physicians. J Am Coll Cardiol 2013;61:1945-1948.

8. Murray B. Arrhythmogenic right ventricular dysplasia/cardiomyopathy (ARVD/C): a review of molecular and clinical literature. J Genet Couns 2012:21:494-504.

9. Romero J, Mejia-Lopez E, Manrique C, Lucariello R. Arrhythmogenic right ventricular cardiomyopathy (ARVC/D): a systematic literature review. Clin Med Insights Cardio/ 2013;7:97-114.

10. Sen-Chowdhry S, Morgan RD, Chambers JC, McKenna WJ. Arrhythmogenic cardiomyopathy: etiology, diagnosis, and treatment. Annu Rev Med 2010;61:233-253.

11. Hodgkinson K. The clinical and genetic epidemiology of ARVC in Newfoundland.. Dissertation, Memorial University: St. John's, Newfoundland, Canada, 2009

12. Merner ND, Hodgkinson KA, Haywood AF, et al. Arrhythmogenic right ventricular cardiomyopathy type 5 is a fully penetrant, lethal arrhythmic disorder caused by a missense mutation in the TMEM43 gene. Am J Hum Genet 2008:82:809-821.

13. Hodgkinson KA, Connors SP, Merner N, et al. The natural history of a genetic subtype of arrhythmogenic right ventricular cardiomyopathy caused by a p.S358L mutation in TMEM43. Clin Genet 2013;83:321-331.

14. Ashley EA, Hershberger RE, Caleshu C, et al.; American Heart Association Advocacy Coordinating Committee. Genetics and cardiovascular disease: a policy statement from the American Heart Association. Circulation 2012;126:142-157

15. Gollob MH, Blier L, Brugada R, et al. Recommendations for the use of genetic testing in the clinical evaluation of inherited cardiac arrhythmias associated with sudden cardiac death: Canadian Cardiovascular Society/Canadian Heart Rhythm Society joint position paper. Can J Cardiol 2011;27:232-245.

16. Marcus Fl, McKenna WJ, Sherrill D, et al. Diagnosis of arrhythmogenic right ventricular cardiomyopathy/dysplasia. Eur Heart J 2010;31:806-14.

17. Shen X, Hodgkinson K, Parfrey P, Young T, Curtis F, Connors S. Ten-year followup of mortality in an ARVD5 cohort after ICD therapy. Canadian Cardiovascular Congress, Montreal, Canada, 23-27 October 2010.

18. Hodgkinson KA, Parfrey PS, Bassett AS, et al. The impact of implantable cardioverter-defibrillator therapy on survival in autosomal-dominant arrhythmogenic right ventricular cardiomyopathy (ARVD5). J Am Coll Cardiol 2005:45:400-408.

19. James CA, Tichnell C, Murray B, Daly A, Sears SF, Calkins H. General and disease-specific psychosocial adjustment in patients with arrhythmogenic right ventricular dysplasia/cardiomyopathy with implantable cardioverter defibrillators: a large cohort study. Circ Cardiovasc Genet 2012;5:18-24.

20. Day SM. Anxiety in patients with arrhythmogenic right ventricular cardiomyopathy and implantable cardioverter defibrillators. Circ Cardiovasc Genet 2012;5:2-4

21. Sandelowski M. Whatever happened to qualitative description? Res Nurs Health 2000;23:334-340

22. Glaser B, Strauss A. The discovery of grounded theory. Chicago, IL: Adeline, 1967.

23. Pope C, Ziebland S, Mays N. Analysing qualitative data. BMJ 2000;320:114-116. 


\section{ORIGINAL RESEARCH ARTICLE}

24. Landfeldt $E$, Lindgren $P$, Bell $C$, et al. The burden of Duchenne muscular dystrophy. Neurology 2014;83:529-536.

25. Angelis A, Tordrup D, Kanavos P. Socio-economic burden of rare diseases: a systematic review of cost of illness evidence. Health Policy 2015;119:964-979.

26. Achelrod D, Blankart CR, Linder R, von Kodolitsch $Y$, Stargardt T. The economic impact of Marfan syndrome: a non-experimental, retrospective, populationbased matched cohort study. Orphanet J Rare Dis 2014;9:90.

27. Kisler J, Whittaker R, McFarland R. Mitochondrial diseases in childhood: a clinical approach to investigation and management. Dev Med Child Neurol 2013;28:663-667.

28. Banerji A. The burden of illness in patients with hereditary angioedema. Ann Allergy Asthma Immunol 2013;111:329-336.

29. Watkins K, Way C, Fiander J, et al. Lynch syndrome: barriers and facilitators of screening and disease management. Hered Cancer Clin Prac 2011;9:8.

30. Forrest Keenan K, Miedzybrodzka Z, van Teijlingen E, McKee L, Simpson SA. Young people's experiences of growing up in a family affected by Huntington's disease. Clin Genet 2007;71:120-129.

31. Williams JK, Ayres L, Specht J, Sparbel K, Klimek ML. Caregiving by teens for family members with Huntington disease. J Fam Nurs 2009;15:273-294.

32. Eijzenga W, Hahn DE, Aaronson NK, Kluijt I, Bleiker EM. Specific psychosocial issues of individuals undergoing genetic counseling for cancer - a literature review. J Genet Couns 2014;23:133-146.
33. Riley BD, Culver JO, Skrzynia C, et al. Essential elements of genetic cancer risk assessment, counseling, and testing: updated recommendations of the National Society of Genetic Counselors. J Genet Couns 2012;21: $151-161$.

34. Kuluski K, Dow C, Locock L, Lyons RF, Lasserson D. Life interrupted and life regained? Coping with stroke at a young age. Int J Qual Stud Health Well-being 2014;9:22252.

35. Bury M. Chronic illness as biographical disruption. Sociol Health IIIn 1982:4:167-182.

36. Charmaz K. Loss of self: a fundamental form of suffering in the chronically ill. Sociol Health Illn 1983;5:168-195.

37. Ell K, Xie B, Wells A, Nedjat-Haiem F, Lee P-J, Vourlekis B. Economic stress among low-income women with cancer. Cancer 2008;112:616-25.

38. Gupta D, Lis CG, Grutsch JF. Perceived cancer-related financial difficulty: implications for patient satisfaction with quality of life in advanced cancer. Support Care Cancer 2007;15:1051-1056.

39. Vassilev I, Rogers A, Sanders C, et al. Social status and living with a chronic illness: an exploration of assessment and meaning attributed to work and employment. Chronic IIIn 2014;10:273-290.

40. Ormondroyd E, Oates S, Parker M, Blair E, Watkins H. Pre-symptomatic genetic testing for inherited cardiac conditions: a qualitative exploration of psychosocial and ethical implications. Eur J Hum Genet 2014;22:88-93. 